\title{
Failure by Simultaneous Grain Growth, Strain Localization, and Interface Debonding in Metal Films on Polymer Substrates
}

\section{Citation}

Lu, Nanshu, Xi Wang, Zhigang Suo, and Joost Vlassak. 2009. Failure by simultaneous grain growth, strain localization, and interface debonding in metal films on polymer substrates. Journal of Materials Research 24(2): 379-385.

\section{Published Version}

doi:10.1557/JMR.2009.0048

\section{Permanent link}

http://nrs.harvard.edu/urn-3:HUL.InstRepos:4276342

\section{Terms of Use}

This article was downloaded from Harvard University's DASH repository, and is made available under the terms and conditions applicable to Open Access Policy Articles, as set forth at http:// nrs.harvard.edu/urn-3:HUL.InstRepos:dash.current.terms-of-use\#OAP

\section{Share Your Story}

The Harvard community has made this article openly available.

Please share how this access benefits you. Submit a story.

\section{Accessibility}


Failure by simultaneous grain growth, strain localization, and interface debonding in metal films on polymer substrates

\author{
Nanshu Lu, Xi Wang, Zhigang Suo, Joost Vlassak \\ School of Engineering and Applied Sciences, Harvard University, Cambridge, MA 02138, USA
}

\begin{abstract}
In a previous paper, we have demonstrated that a microcrystalline copper film well bonded to a polymer substrate can be stretched beyond 50\% without cracking. The film eventually fails through the co-evolution of necking and debonding from the substrate. Here we report much lower strains to failure (around 10\%) for polymer-supported nanocrystalline metal films, whose microstructure is revealed to be unstable under mechanical loading. We find that strain localization and deformation-associated grain growth facilitate each other, resulting in an unstable deformation process. Film/substrate delamination can be found wherever strain localization occurs. We therefore propose that three concomitant mechanisms are responsible for the failure of a plastically deformable but microstructurally unstable thin metal film: strain localization at large grains, deformation-induced grain growth and film debonding from the substrate.
\end{abstract}

Keywords: Cu films, Kapton, grain growth, strain localization, debonding 


\section{Introduction}

Flexible electronics are being developed for diverse applications, such as paper-like displays that can be folded or rolled [1], electronic skins for robots and humans [2], drapeable and conformable electronic textiles [3], and flexible solar cells providing portable and renewable source of energy [4]. In some designs, small islands of stiff functional materials and thin metal interconnects are deposited on a polymer substrate. When the structure is stretched, the stiff islands experience small strains, but the metal interconnects must deform along with the substrate. Such considerations have motivated us to study the behavior of polymer-supported metal films undergoing large deformation.

A polymer-supported metal film behaves differently from a freestanding metal film. When stretched, a freestanding film of a ductile metal ruptures by forming a neck within a narrow region. Although strain within the neck is large, strain elsewhere in the film is small. Recall that the film typically has an extraordinarily large length-to-thickness ratio. Consequently, the net elongation of the freestanding film upon rupture is small, typically less than a few percent [5-9].

For a ductile metal film well bonded to a polymer substrate, finite element simulations have shown that the polymer substrate can retard necking in the metal film, so that the film can elongate infinitely, limited only by rupture of the polymer substrate $[10,11]$. Experimentally, however, most polymer-supported thin metal films rupture at small elongations $(<10 \%)[12-19]$, even though elongations as high as $20 \%$ have been reported in a few cases [20-22]. Our recent experiments, on the other hand, have achieved very large elongations (more than 50\%) [23] and have demonstrated that good adhesion between film and substrate is critical to achieving these 
large elongations, an observation that is consistent with both theoretical predictions [11] and a previous experimental investigation [18].

Good adhesion is not the only condition needed to achieve large elongation. It is also essential to keep the deformation as uniform as possible. In our previous experiments [23], copper films were sputter-deposited on Kapton substrates and then annealed to allow grains to grow. The thermal treatment stabilized the microstructure of the films and the grain size was normally distributed. In this paper, we focus on the behavior of as-deposited $\mathrm{Cu}$ films with an average grain size around $90 \mathrm{~nm}$ and a bimodal grain size distribution. Compared to annealed films, these as-deposited films have a much smaller strain-to-failure. The heterogeneous microstructure of these films is detrimental to the overall deformation behavior of the films due to the strong grain-size-dependence of the $\mathrm{Cu}$ flow stress [24]. We will show that the early rupture of these films can indeed be attributed to the nonuniform initial microstructure of the films and to the grain growth that occurs in these films during deformation.

Grain growth during deformation has been reported in other nano-crystalline materials. For instance, grain growth has been detected in nano-crystalline $\mathrm{Cu}$ during microhardness testing at both cryogenic and room temperatures [25]. In-situ nanoindentation of nano-grained Al films on $\mathrm{Si}$ wedges have demonstrated rapid grain boundary migration and coalescence during deformation [26]. Grain growth has also been observed in freestanding nano-crystalline Al films when subjected to uniaxial tension at room temperature [27]. Even though the precise mechanism of deformation-induced grain growth remains under investigation, we are concerned about its consequences. Indeed, we will show that this grain growth coupled with strain 6/11/2008 8:53:17 PM 
localization and delamination is the cause of early failure in as-deposited $\mathrm{Cu}$ films on polymer substrates.

This paper is organized as follows. Section 2 elaborates on the experimental set up and procedures. In Section 3, we first show the remarkable difference in electrical resistance as a function of elongation between annealed and unannealed films. We then explain this difference in terms of microstructure evolution and film fracture. Evidence of grain growth in unannealed films under mechanical loading is provided and its consequences are discussed. Based on our measurements and observations, a failure mechanism involving three concurrent phenomena is proposed. Final conclusions are given in Section 4.

\section{Experimental}

The polymer substrates used in this study were $12.7 \mu \mathrm{m}$ thick polyimide foils (Kapton $50 \mathrm{HN} \circledast$ by DuPont). The substrates were first ultrasonically cleaned with acetone and methanol. Then the substrates were covered by a shadow mask with seven $5 \times 50 \mathrm{~mm}$ rectangular windows to define the coating area. The covered substrates were put inside the chamber of a direct-current (dc) magnetron sputter-deposition system with a base pressure better than $1 \times 10^{-7} \mathrm{Torr}$, and were sputter cleaned for 5 minutes using an Ar plasma at a radio-frequency power of $24 \mathrm{~W}$ and a pressure of $2 \times 10^{-2}$ Torr. Immediately after sputter cleaning, a $1 \mu \mathrm{m} \mathrm{Cu}$ layer was deposited onto the substrates through the windows in the shadow mask. The deposition was performed using a $50.8 \mathrm{~mm} \mathrm{Cu}$ target at a dc power of $200 \mathrm{~W}$ and a working gas (Ar) pressure of $5 \times 10^{-3}$ Torr. The nominal target-substrate distance was $100 \mathrm{~mm}$ and the corresponding deposition rate was 
approximately $0.39 \mathrm{~nm} / \mathrm{s}$. The coated Kapton wafer was taken out of the vacuum chamber half an hour after the deposition. For comparison, another set of $\mathrm{Cu}$ films was annealed at $200^{\circ} \mathrm{C}$ for 30 minutes inside the sputter chamber, immediately after the deposition and without breaking vacuum. These annealed specimens were removed from the vacuum chamber after 12 hours to allow them to cool down prior to breaking vacuum. Figure 1 shows FIB (Focused Ion Beam) images of the $\mathrm{Cu}$ surface before and after anneal. In general the grain size is much larger after the heat treatment, although a few large grains can also be found in as-deposited specimens. Additional annealing did not further increase the grain size. This observation is consistent with the theoretical prediction that grain growth in a film is constrained by the thickness of the film [28].

Tensile test specimens with a width of $5 \mathrm{~mm}$ were cut from the coated substrates using a razor blade. They were then subjected to uniaxial tension using an Instron 3342 tensile tester. All tests were performed at room temperature with a specimen gauge length $L_{0}=30 \mathrm{~mm}$ and at a constant strain rate of $3.33 \times 10^{-4} \mathrm{~s}^{-1}$. During tensile testing, the electrical resistance of the films was measured in situ using a Keithley 2000 multimeter in a four-point measurement set up.

The surface morphology and cross-sections of deformed and undeformed $\mathrm{Cu}$ films were characterized using a FEI Dual-Beam focused ion beam/scanning electron microscope (FIB/SEM). The SEM produces high-resolution images of a sample surface by focusing an electron beam onto the surface of a sample and detecting secondary electrons generating from the interaction of the incident electrons with the sample surface. The FIB uses a focused beam of high energy gallium ions to image the sample. Because of ion channelling, FIB images have 6/11/2008 8:53:17 PM 
much stronger orientation contrast. Consequently it is much easier to identify individual grains in an FIB micrograph than in an SEM micrograph.

\section{Results and Discussions}

\subsection{Resistance deviation induced by film cracking}

We adopt an equation relating the electrical resistance of the intact metal films to its elongation by following the same argument as in our previous paper [23]. Let $R$ be the resistance of the metal film, which is stretched to length $L$ and cross-sectional area $A$. Let $R_{0}$, $L_{0}$ and $A_{0}$ be the corresponding initial values. Assuming no cracks have formed, the ratio of the resistance of the strained film to the resistance of the unstrained film is

$$
R / R_{0}=\left(L / L_{0}\right)^{2} .
$$

Equation (1) implicitly assumes that the electrical resistivity of the films does not change during plastic deformation of the film. Figure 2 plots the normalized resistance $R / R_{0}$ as a function of the normalized length $L / L_{0}$ for both as-deposited and annealed specimens. The dashed line is the theoretical prediction according to Eq. (1). The resistance of as-deposited films deviates rapidly from the guideline at an elongation of approximately $12 \%$. This sudden departure in the film resistance is caused by the formation and propagation of cracks in the $\mathrm{Cu}$ films, as confirmed by post-mortem SEM observations (Fig. 3). Isolated microcracks are observed at low magnification after the specimen is strained by $15 \%$ (Fig. 3a). Cracks become interconnected and severe debonding can be observed at an elongation of $40 \%$, as is evident in Fig. 3(b). The micrographs in Figs. 3(c) and (d) provide a closer look at the crack morphology for elongations of 15\% and 
$40 \%$, respectively. Significant plastic flow is evident from the saw-tooth profile of the crack faces.

The behaviour of annealed specimens is distinctly different. Fig. 2 shows that the resistance of annealed films starts to slowly deviate from the guideline at an elongation of $25 \%$, indicating very little cracking. This observation was confirmed by post-mortem SEM microscopy. Typical micrographs are shown in Fig. 4. Films deformed to 30\% (Fig. 4a) and to 50\% strain (Fig. 4b) show clear evidence of fracture, although the crack density is much lower than in as-deposited films. Films deformed less than $25 \%$, on the other hand, do not show any evidence of fracture (not shown). The deviation from the theoretical resistance curve is only induced by the formation of cracks in the film and not by an increase in dislocation density as a result of plastic deformation. We know this because very similar $\mathrm{Cu}$ films on Kapton substrates, but with a thin Ti or $\mathrm{Cr}$ adhesion layer to improve bonding to the substrate, can be plastically deformed to $50 \%$ without any appreciable deviation from the theoretical resistance curve [23]. At higher magnification, both intra- and inter-granular cracks can be observed in the annealed films (Fig. $4 \mathrm{c}$ and d). Slip traces are also clearly visible within each grain, indicative of the extensive plastic deformation that occurred in these films. Cross-sectional images of the cracked regions (Fig. 3 in Ref. [23]) reveal that annealed $\mathrm{Cu}$ films eventually rupture through co-evolution of necking and debonding from the substrates, in good agreement with finite element simulations [10, 11].

\subsection{Unstable microstructure of as-deposited films during deformation}


While the microstructure of the annealed copper films is stable under mechanical loads, the microstructure of the as-deposited films is not. Evidence of grain growth in the as-deposited films during deformation is presented in Fig. 5, which shows the evolution of the grain structure during deformation. Figure 5(a) shows a plan view of an undeformed, as-deposited $\mathrm{Cu}$ film immediately after deposition. Although most grains are less than $90 \mathrm{~nm}$ in size, there are a few large grains of micron size embedded in the matrix of nano-grains. Few if any twin boundaries can be identified in the film. Figure 5(b) shows a micrograph of the same undeformed specimen taken six hours after deposition. There is no significant difference in grain size distribution, indicating that no grain growth takes place in undeformed specimens at room temperature on the timescale of the experiment. Figures 5(c) and (d) are post-mortem FIB micrographs of specimens stretched to $10 \%$ and $15 \%$ strains respectively, also taken six hours after deposition. The only difference between the specimen shown in Fig. 5(b) and those shown in Figs. 5(c) and (d) is that the latter two were plastically deformed. As is evident from the micrographs, there are significant microstructural differences between the specimens: while a few isolated large grains can be observed in undeformed specimen, the deformed films contain many such grains. Grain growth is clearly discontinuous in that a strong bimodal grain size distribution develops. Several mechanisms have been described to explain discontinuous grain growth in nano-crystalline metal films [27]. These include grain growth driven by a reduction in surface energy [29], elastic strain energy [30], or stored deformation energy [31]. A simple energy calculation shows, however, that the driving forces for these mechanisms are smaller than for continuous grain growth. Stress-driven grain growth has also been observed experimentally in nano-crystalline Al films. 6/11/2008 8:53:17 PM 
Indeed, both molecular dynamics (MD) simulations [32, 33] and experimental measurements on bicrystals [34-36] suggest that grain boundaries can migrate as a result of an applied shear stress. At this point, it is not clear whether grain growth in these $\mathrm{Cu}$ films is stress or strain driven. In the context of this study, however, the precise mechanism for grain growth is not that important: We will show that grain growth contributes to early strain localization and hence premature failure of the as-deposited films independent of the precise grain growth mechanism.

\subsection{Simultaneous strain localization and grain growth}

To understand the mechanism of rupture in as-deposited films we first review the more straightforward case, i.e., fracture of annealed copper films under uniaxial tension. From a comparison of Figs. 1(a) and (b), it is evident that annealed specimens have a more uniform microstructure than as-deposited films, with a relatively large grain size of $1.5 \mu \mathrm{m}$. Moreover, the microstructure of the annealed films remains stable during the deformation, i.e., no grain growth takes place during plastic deformation. Consequently the annealed films deform relatively homogenously until simultaneous delamination and strain localization lead to failure of the films [23].

In contrast, as-deposited specimens have a bimodal grain size distribution: they are mostly nano-crystalline with a few large grains. The nano-crystalline sections of the films have a very high yield strength as a result of the Hall-Petch effect [29]. The large grains, on the other hand, are much easier to plastically deform. Such a microstructure naturally leads to nonuniform deformation. Furthermore, it is evident from Fig. 5 that the number of large grains increases 
during plastic deformation. This microstructure leads to deformation behavior that is significantly different from that of annealed films. Figure 6 shows two sets of micrographs taken by SEM and FIB of samples that were stretched by 15 and $30 \%$. The SEM images show the surface topography, while the FIB images show the grain structure of the same areas of the films. Incipient necks can be observed in the SEM images (Figs. 6a and 6c). The corresponding FIB images in Figs. 6(b) and 6(d), and many others like them, show that these necks are associated with one or more large grains in the film. At 15\% strain, the FIB image (Fig. 6b) shows that there are initially many nano-crystalline grains in the necked down area, even though the necks are usually associated with at least one large grain. At 30\% strain, however, most of these small grains have disappeared and the areas of strain localization contain mostly large grains. Strain localization and large grains are closely correlated for sufficiently large deformations.

These observations are readily understood as follows. According to the Hall-Petch effect, there is an inverse relationship between the yield strength and the grain size of a polycrystalline material as long as the grain size is above a few tens of nanometers. As a result, the nano-crystalline regions of the films have a much larger yield strength than the large grains, i.e., the large grains can be regarded as soft inclusions embedded in a hard matrix. Under tensile loading, the softer regions will tend to concentrate the deformation. Therefore initial strain localizations are associated with large grains. As these localizations grow they engulf adjacent nano-crystalline regions. As these nano-crystalline regions deform, they undergo grain growth, making it easier for them to plastically deform and thus further localizing deformation. The two 
mechanisms, strain localization and grain growth, facilitate each other and lead to ductile film rupture at relatively small overall strains as shown in Figs. 3(c) and (d).

\subsection{Concomitant debonding}

For strain localization to take place and carry on, a third mechanism is required film/substrate debonding. The argument is the same as in annealed films: debonding makes the film locally freestanding so that necking of the film can be accommodated by a local elongation of the freestanding portion of the film. If there is no strain localization, there is no traction exerted on the interface to initiate debonding; if there is no debonding to release the constraint from the substrate, there is no space for large local deformation in the metal film to take place.

To validate this interpretation, Fig. 7 shows cross-sectional images of unannealed specimens deformed to different elongations. Strain localization and debonding always co-evolve. Figure 7(a) shows a uniform $\mathrm{Cu}$ film well bonded to Kapton substrate prior to any deformation. The FIB image confirms that the grains do not have a columnar structure because multiple grains can be found through the film thickness. In Fig. 7(b) at 10\% strain, local thinning has taken place along with debonding from the substrate, but few cracks can be found in the specimens. As illustrated in Fig. 7(c), microcracks can be observed in samples with an elongation of $20 \%$. It is obvious that these cracks occur in regions of intense plastic deformation with local thinning and debonding. In conclusion, simultaneous strain localization and debonding are necessary ingredients for the rupture of a ductile film supported by a stretchable substrate. From this point of view there is no difference between annealed and as-deposited films. 
The failure mode of as-deposited $\mathrm{Cu}$ films on polymer substrate is illustrated schematically in Fig. 8. Initially, the as-deposited film is mostly composed of nano-crystalline material with occasional micron-sized grains. Under tensile loading, large grains act as preferential sites for strain localization. Nano-crystalline grains in regions of strain localization start to grow with increasing strain, locally weakening the material and further promoting localization. As strain localization proceeds, tractions are exerted on the film/substrate interface. These tractions cause local delamination of the film, freeing it from the constraint of the underlying substrate. This process, in turn, promotes strain localization. Eventually the film necks down to a knife-edge. Micro-cracks form in the film and the resistance of the film increases suddenly. In short, the as-deposited $\mathrm{Cu}$ films fail through three concurrent mechanisms: strain localization at big grains, deformation-induced grain growth, and debonding from the substrate.

\section{Conclusions}

We have conducted a series of experiments on as-deposited and annealed $\mathrm{Cu}$ films supported by stretchable polyimide substrates to investigate the failure modes of polycrystalline $\mathrm{Cu}$ films under large deformation. Subjected to tensile loading, as-deposited films rupture much earlier than annealed films. This early failure is attributed to the grain structure of the films, which is inhomogeneous and unstable under loading. We demonstrate that the films fail by ductile necking as a result of strain localization at large grains, deformation-associated grain growth, and film debonding from the substrate. 


\section{Acknowledgments}

This work was supported by the NSF under grant CMS-0556169, and by the MRSEC at

Harvard University. The authors would like to thank David Mooney for use of the Instron tensile tester. 
1. S.R. Forrest: The path to ubiquitous and low-cost organic electronic appliances on plastic. Nature 428, 911 (2004).

2. S. Wagner, S.P. Lacour, J. Jones, P.I. Hsu, J.C. Sturm, T. Li, and Z. Suo: Electronic skin: Architecture and components. Physica E 25, 326 (2005).

3. E. Bonderover, and S. Wagner: A woven inverter circuit for e-textile applications. IEEE Electr. Device L. 25, 295 (2004).

4. C.J. Brabec: Organic photovoltaics: Technology and market. Sol. Energ. Mat. Sol. C. 83, 273 (2004).

5. R.R. Keller, J.M. Phelps, and D.T. Read: Tensile and fracture behavior of free-standing copper films. Mater. Sci. Eng. A-Struct. 214, 42 (1996).

6. H. Huang, and F. Spaepen: Tensile testing of free-standing $\mathrm{Cu}, \mathrm{Ag}$ and $\mathrm{Al}$ thin films and Ag/Cu multilayers. Acta Mater. 48, 3261 (2000).

7. Y. Xiang, X. Chen, and J.J. Vlassak: The mechanical properties of electroplated Cu thin films measured by means of the bulge test technique, in Thin Films: Stresses and Mechanical Properties IX, edited by C.S. Ozkan, L.B. Freund, R.C. Cammarata, and H. Gao (Mater. Res. Soc. Symp. Proc. 659, Boston, MA, 2002), L4.9.

8. H.D. Espinosa, B.C. Prorok, and M. Fischer: A methodology for determining mechanical properties of freestanding thin films and mems materials. J. Mech. Phys. Solids 51, 47 (2003). 9. H.J. Lee, P. Zhang, and J.C. Bravman: Tensile failure by grain thinning in micromachined aluminum thin films. J. Appl. Phys. 93, 1443 (2003). 
10. T. Li, Z.Y. Huang, Z.C. Xi, S.P. Lacour, S. Wagner, and Z. Suo: Delocalizing strain in a thin metal film on a polymer substrate. Mech. Mater. 37, 261 (2005).

11. T. Li, and Z. Suo: Ductility of thin metal films on polymer substrates modulated by interfacial adhesion. Int. J. Solids Struct. 44, 1696 (2006).

12. S.L. Chui, J. Leu, and P.S. Ho: Fracture of metal-polymer line structures. 1. Semiflexible polyimide. J. Appl. Phys. 76, 5136 (1994).

13. O. Kraft, M. Hommel, and E. Arzt: X-ray diffraction as a tool to study the mechanical behaviour of thin films. Mater. Sci. Eng. A-Struct. 288, 209 (2000).

14. M. Hommel, and O. Kraft: Deformation behavior of thin copper films on deformable substrates. Acta Mater. 49, 3935 (2001).

15. B.E. Alaca, M.T.A. Saif, and H. Sehitoglu: On the interface debond at the edge of a thin film on a thick substrate. Acta Mater. 50, 1197 (2002).

16. S.P. Lacour, S. Wagner, Z. Huang, and Z. Suo: Stretchable gold conductors on elastomeric substrates. Appl. Phys. Lett. 82, 2404 (2003).

17. D.Y.W. Yu, and F. Spaepen: The yield strength of thin copper films on kapton. J. Appl. Phys. 95, 2991 (2003).

18. Y. Xiang, T. Li, Z. Suo, and J.J. Vlassak: High ductility of thin metal film adherent on polymer substrate. Appl. Phys. Lett. 87, 161910 (2005).

19. R.M. Niu, G. Liu, C. Wang, G. Zhang, X.D. Ding, and J. Sun: Thickness dependent critical strain in submicron cu films adherent to polymer substrate. Appl. Phys. Lett. 90, 161907 (2007). 
20. Y.S. Kang: Microstructure and strengthening mechanisms in aluminum thin films on polyimide film. Ph.D. Thesis. (the University of Texas at Austin, 1996).

21. F. Macionczyk, and W. Bruckner: Tensile testing of $\mathrm{AlCu}$ thin films on polyimide foils. J. Appl. Phys. 86, 4922 (1999).

22. P. Gruber, J. Böhm, A. Wanner, L. Sauter, R. Spolenak, and E. Arzt: Size effect on crack formation in $\mathrm{Cu} / \mathrm{Ta}$ and $\mathrm{Ta} / \mathrm{Cu} / \mathrm{Ta}$ thin film systems, in Nanoscale Materials and Modeling-Relations Among Processing, Microstructure and Mechanical Properties, edited by P.M. Anderson, T. Foecke, A. Misra, R.E. Rudd (Mater. Res. Soc. Symp. Proc. 821, San Francisco, CA, 2003), P2.7.

23. N. Lu, X. Wang, Z. Suo, and J.J. Vlassak: Metal films on polymer substrates strained beyond 50\%. Appl. Phys. Lett. 91, 221909 (2007).

24. M.A. Meyers, A. Mishra, and D.J. Benson: Mechanical properties of nanocrystalline materials. Prog. Mater. Sci. 51, 427 (2006).

25. K. Zhang, J.R. Weertman, and J.A. Eastman: Rapid stress-driven grain coarsening in nanocrystalline cu at ambient and cryogenic temperatures. Appl. Phys. Lett. 87, 061921 (2005). 26. M. Jin, A.M. Minor, E.A. Stach, and J.W. Morris: Direct observation of deformation-induced grain growth during the nanoindentation of ultrafine-grained $\mathrm{Al}$ at room temperature. Acta Mater. 52, 5381 (2004).

27. D.S. Gianola, S. Van Petegem, M. Legros, S. Brandstetter, H. Van Swygenhoven, and K.J. Hemker: Stress-assisted discontinuous grain growth and its effect on the deformation behavior of nanocrystalline aluminum thin films. Acta Mater. 54, 2253 (2006). 
28. C.V. Thompson: Structure evolution during processing of polycrystalline films. Annu. Rev. Mater. Sci. 30, 159 (2000).

29. M. McLean, and B. Gale: Surface energy anisotropy by an improved thermal grooving technique. Philos. Mag. 20, 1033 (1969).

30. E.M. Zielinski, R.P. Vinci, and J.C. Bravman: The influence of strain energy on abnormal grain growth in copper thin films. Appl. Phys. Lett. 67, 1078 (1995).

31. G. Gottstein, and L.S. Shvindlerman: Grain boundary migration in metals: thermodynamics, kinetics, applications. (CRC Press, Boca Raton, FL, 1999).

32. J.W. Cahn, and J.E. Taylor: A unified approach to motion of grain boundaries, relative tangential translation along grain boundaries, and grain rotation. Acta Mater. 52, 4887 (2004)

33. A. Suzuki, and Y. Mishin: Atomic mechanisms of grain boundary motion. Mater. Sci. Forum 502, 157 (2005).

34. M. Winning, G. Gottstein, and L.S. Shvindlerman: Migration of grain boundaries under the influence of an external shear stress. Mater. Sci. Eng. A-Struct. 317, 17 (2001).

35. M. Winning, G. Gottstein, and L.S. Shvindlerman: On the mechanisms of grain boundary migration. Acta Mater. 50, 353 (2002).

36. D.A. Molodov, V.A. Ivanov, and G. Gottstein: Low angle tilt boundary migration coupled to shear deformation. Acta Mater. 55, 1843 (2007). 

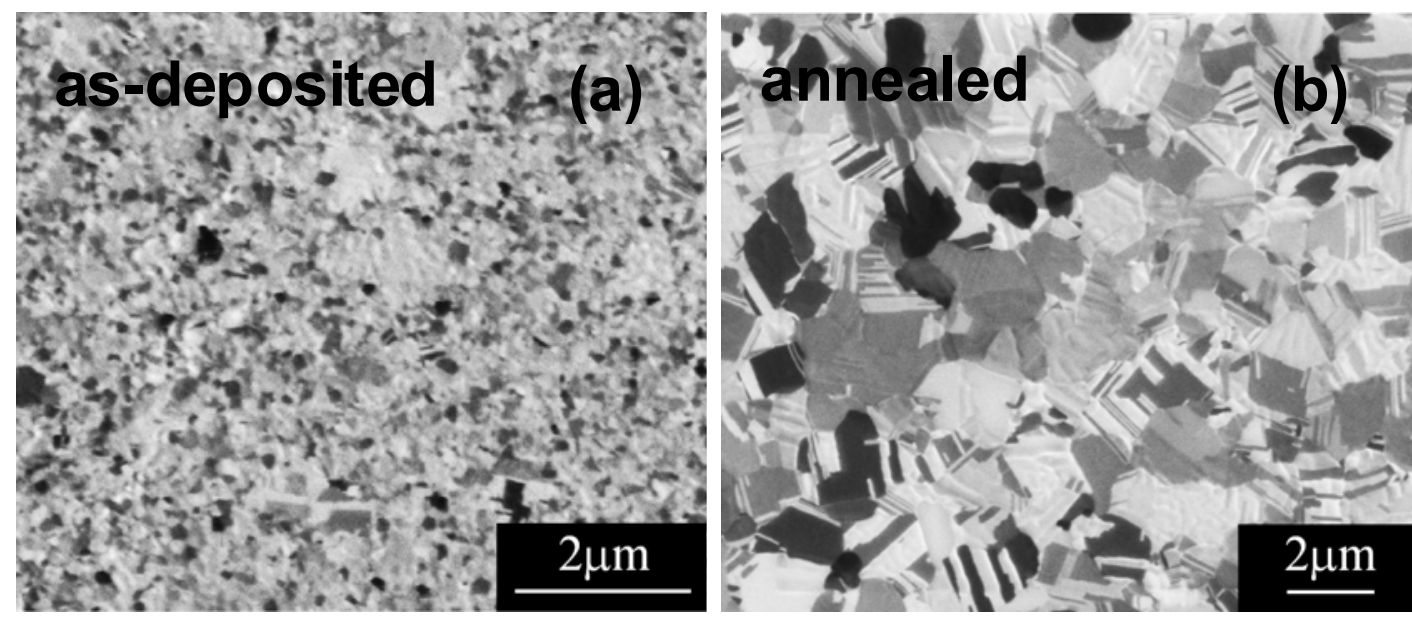

Figure 1. FIB images of (a) as-deposited film and, (b) film annealed at $200^{\circ} \mathrm{C}$ for 30 minutes.

The anneal has caused significant grain growth. While grains have a relatively uniform distribution in the annealed film, isolated large grains can be identified in the as-deposited film. 


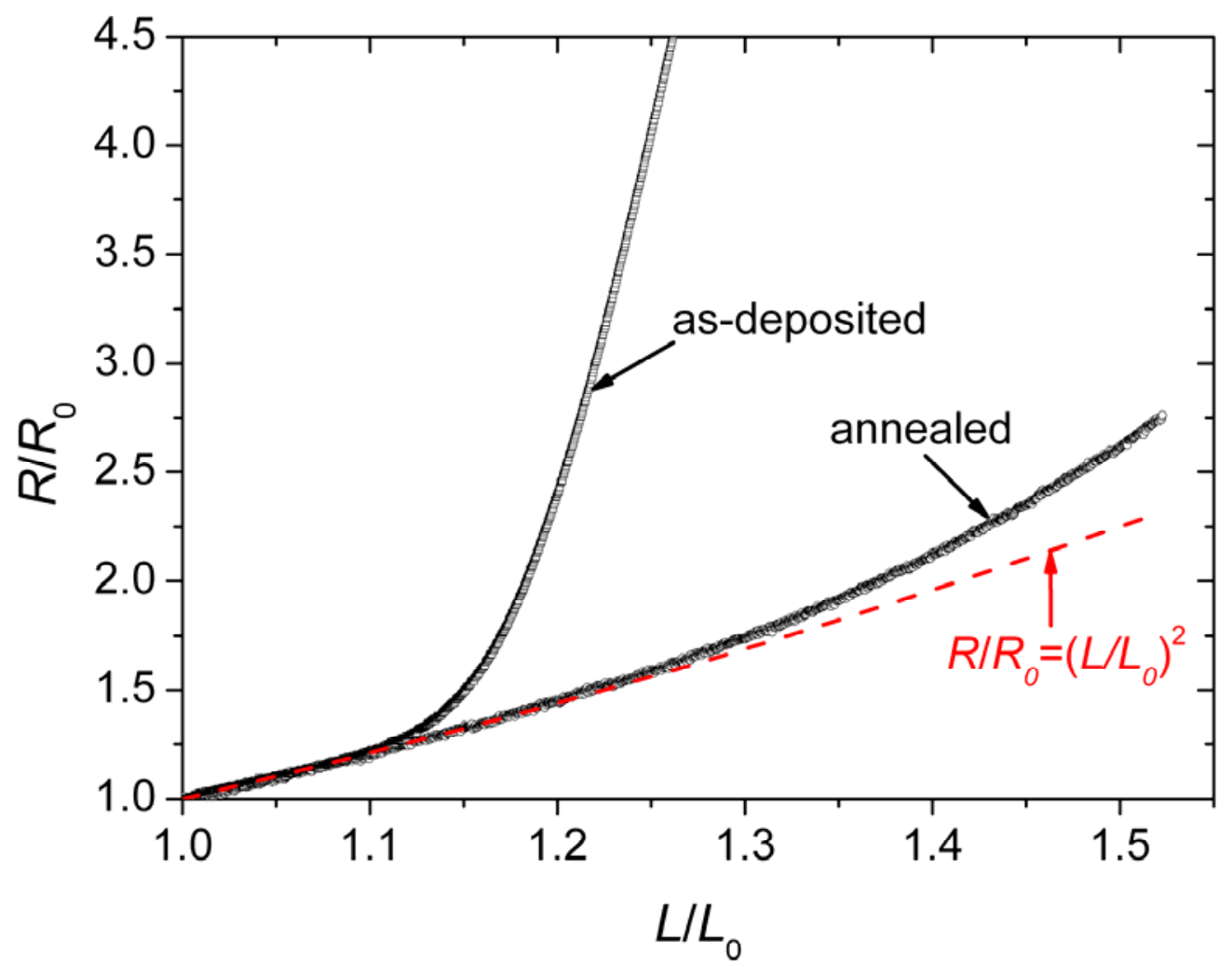

Figure 2. When a metal film on a polymer substrate was pulled, the electrical resistance $R$ of the film increased with the length $L$ of the film. The resistance and the length are normalized by their initial values, $R_{0}$ and $L_{0}$. The theoretical prediction, $R / R_{0}=\left(L / L_{0}\right)^{2}$, assumes that the film deforms homogenously and that the resistivity is unaffected by the deformation. The measured resistance of the as-deposited film starts to blow up at an elongation about $12 \%$, while that of the annealed film starts to deviate from the theoretical prediction at an elongation about $25 \%$. 

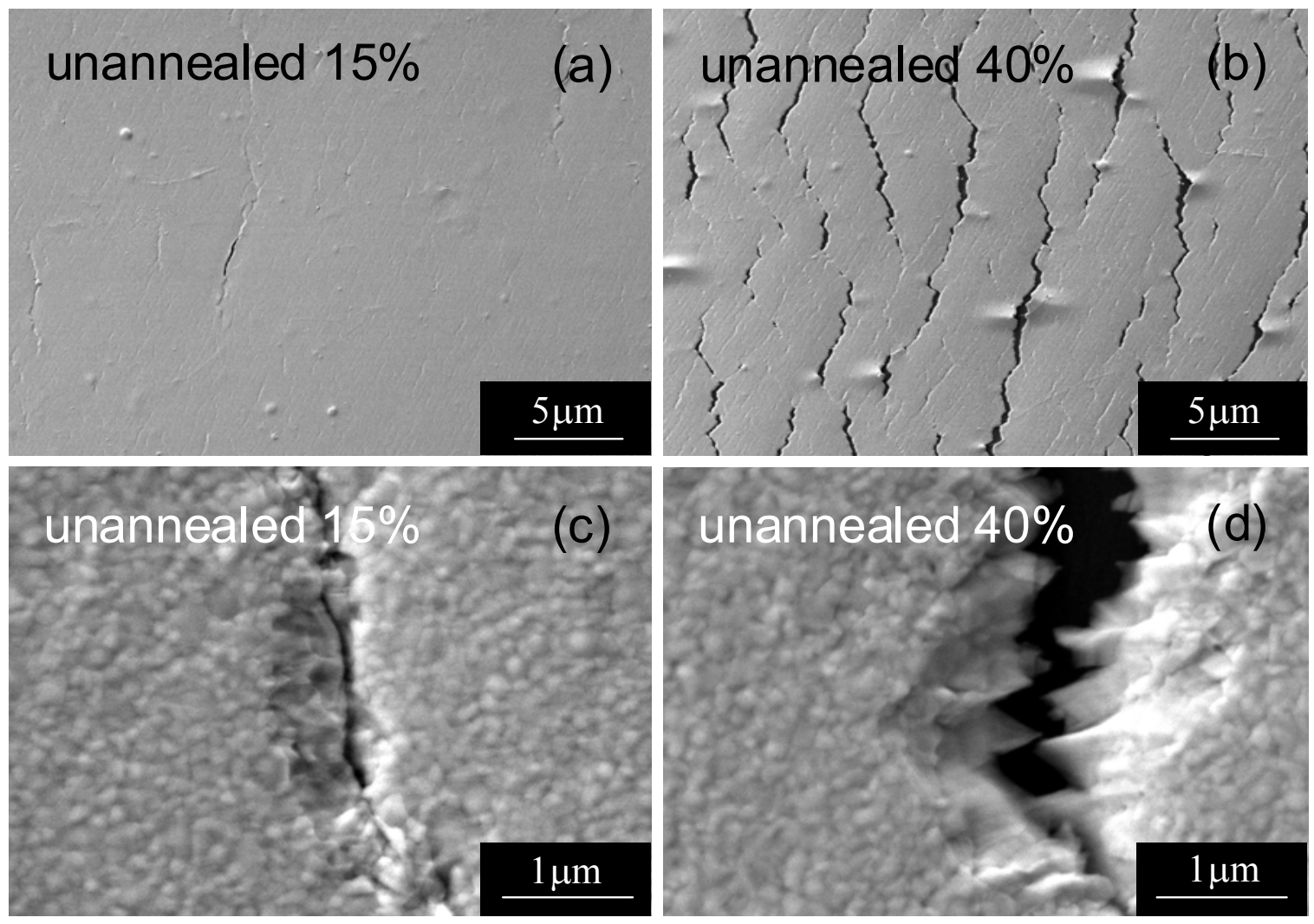

Figure 3. SEM images of as-deposited films after deformation of (a) $15 \%$ and (b) $40 \%$.

Multiple neckings and isolated cracks can be found at an elongation of $15 \%$ whereas denser and interconnected cracks appear after 40\% deformation. (c) and (d) show cracks of higher magnification at $15 \%$ and $40 \%$ strain. Large local elongation along crack path and saw-tooth profile are indications of significant plastic flow. 

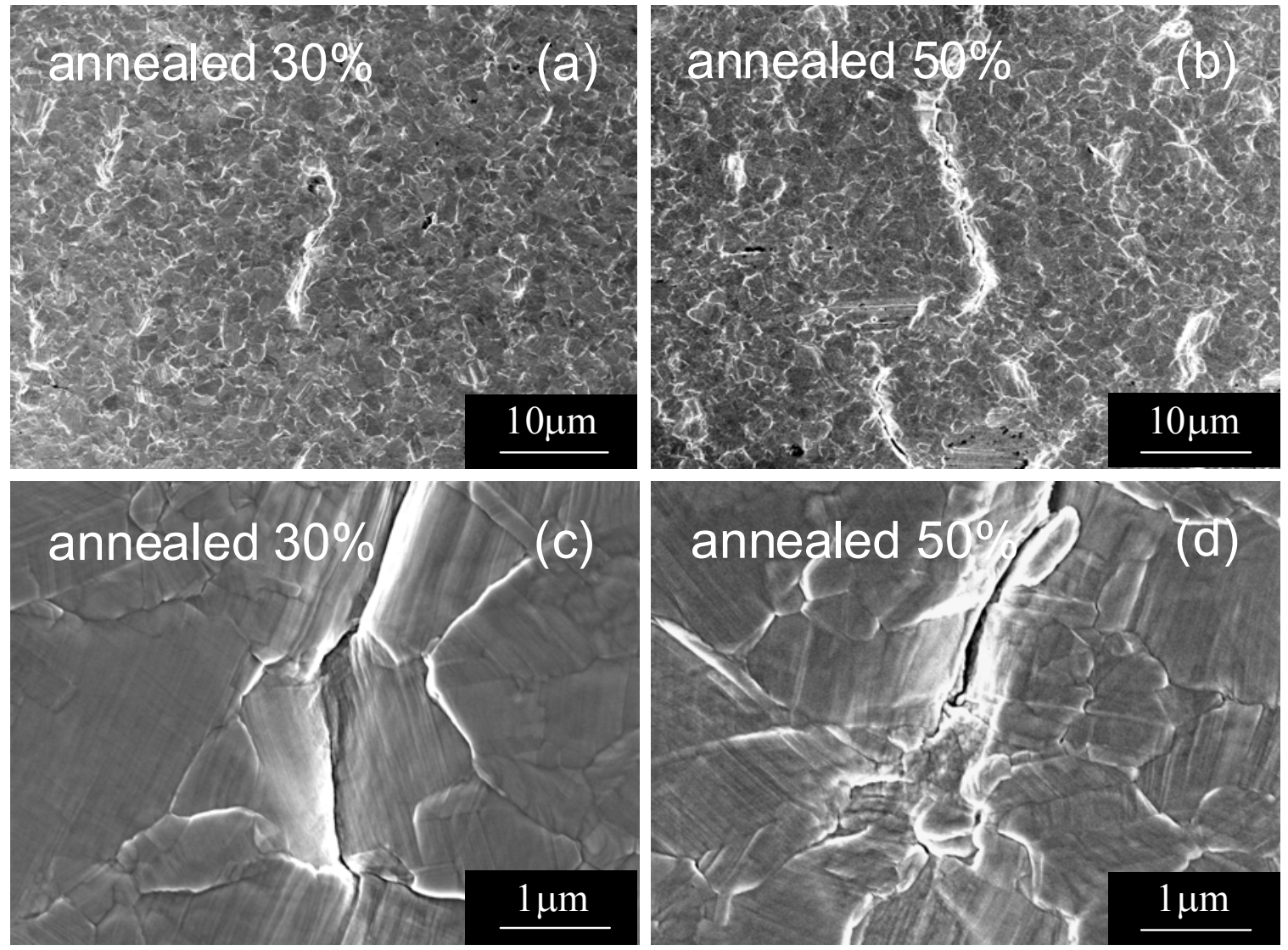

Figure 4 SEM images of surface morphology of annealed films at strains of (a) 30\% and (b) 50\% at a low magnification. Few cracks can be observed at strains of 30\% strain and slightly more can be found after strain of 50\%. (c) and (d) show crack details at a higher magnification. Slip traces of dislocations are identified as parallel deformation lines within each grain. The fracture is both transgranular and intergranular. 

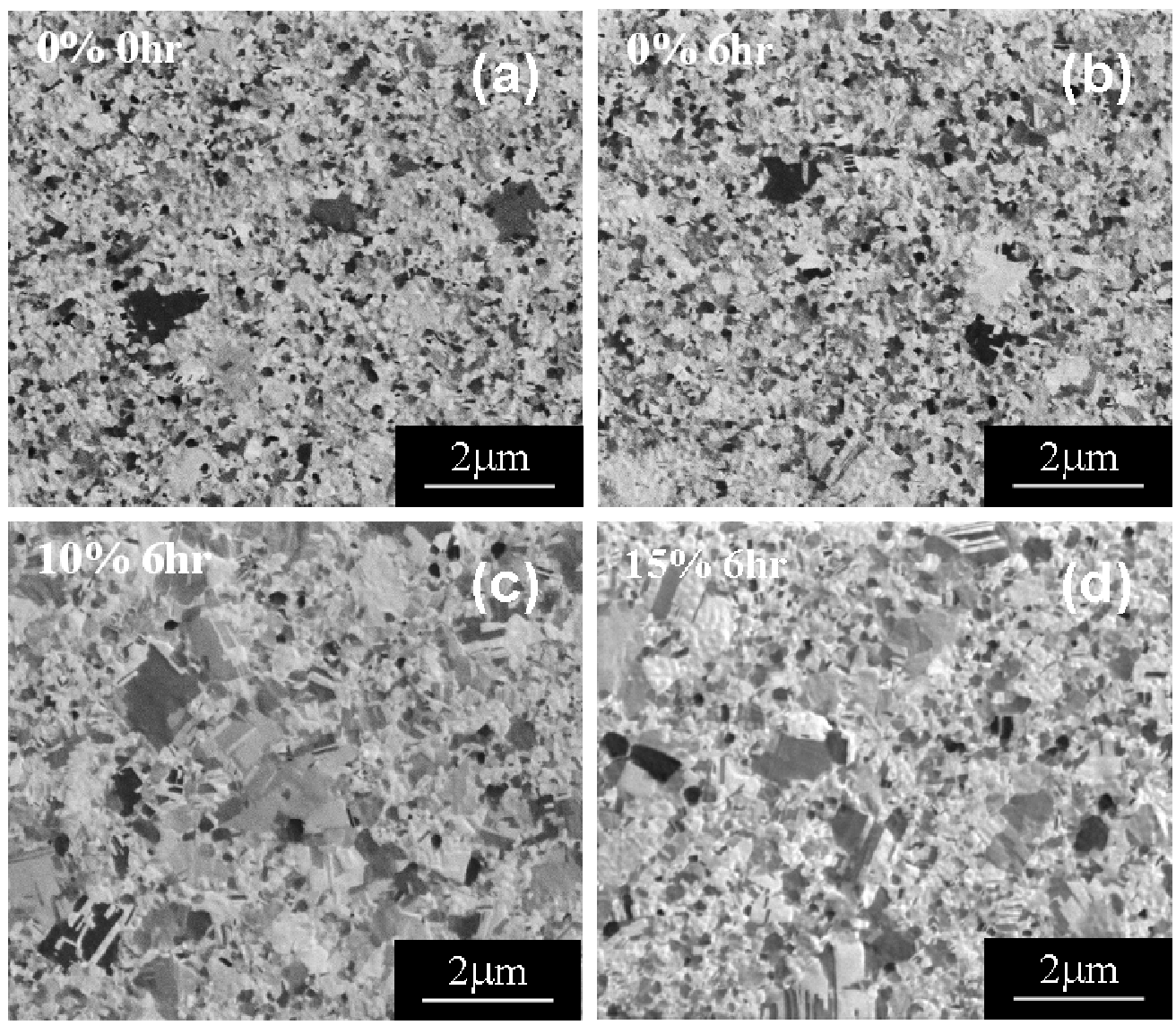

Figure 5. FIB images of films held at room temperature afterwards. (a) right after deposition.

(b) 6 hours after deposition, subject to no load.

(c) 6 hours after deposition, pulled by a strain

of $10 \%$. (d) 6 hours after deposition, pulled by a strain of $20 \%$. A comparison of (a) and (b) indicates that the size of grains remained unchanged for a film subject no load. A comparison of (b), (c) and (d) indicates that the size of grains markedly increased when the film is pulled by $10 \%$ and $15 \%$. 

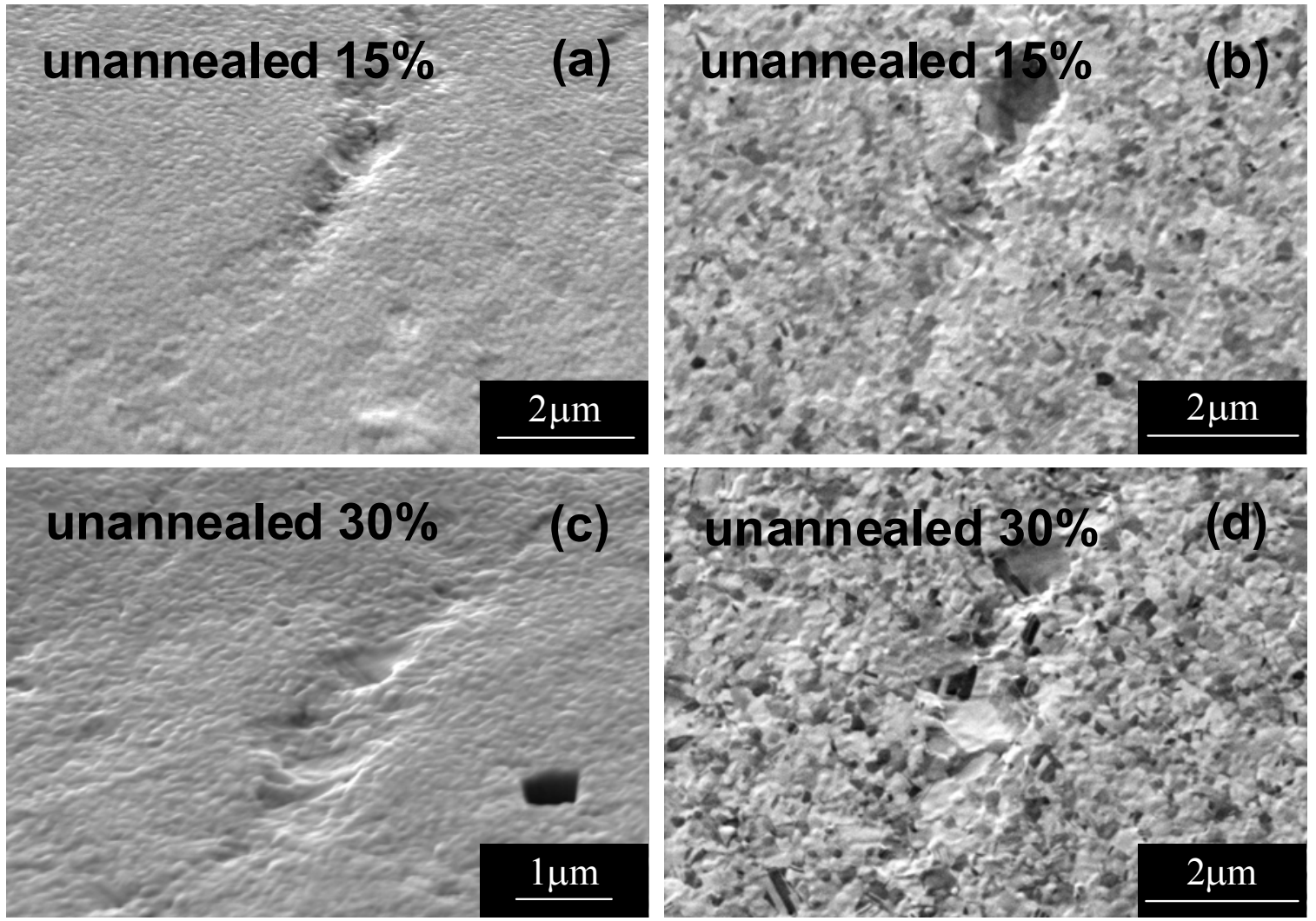

Figure 6. Images of strain localization in as-deposited films pulled by (a) \& (b) $15 \%$, (c) \& (d)

$30 \%$. Severely necked region always contains at least one large grain. 

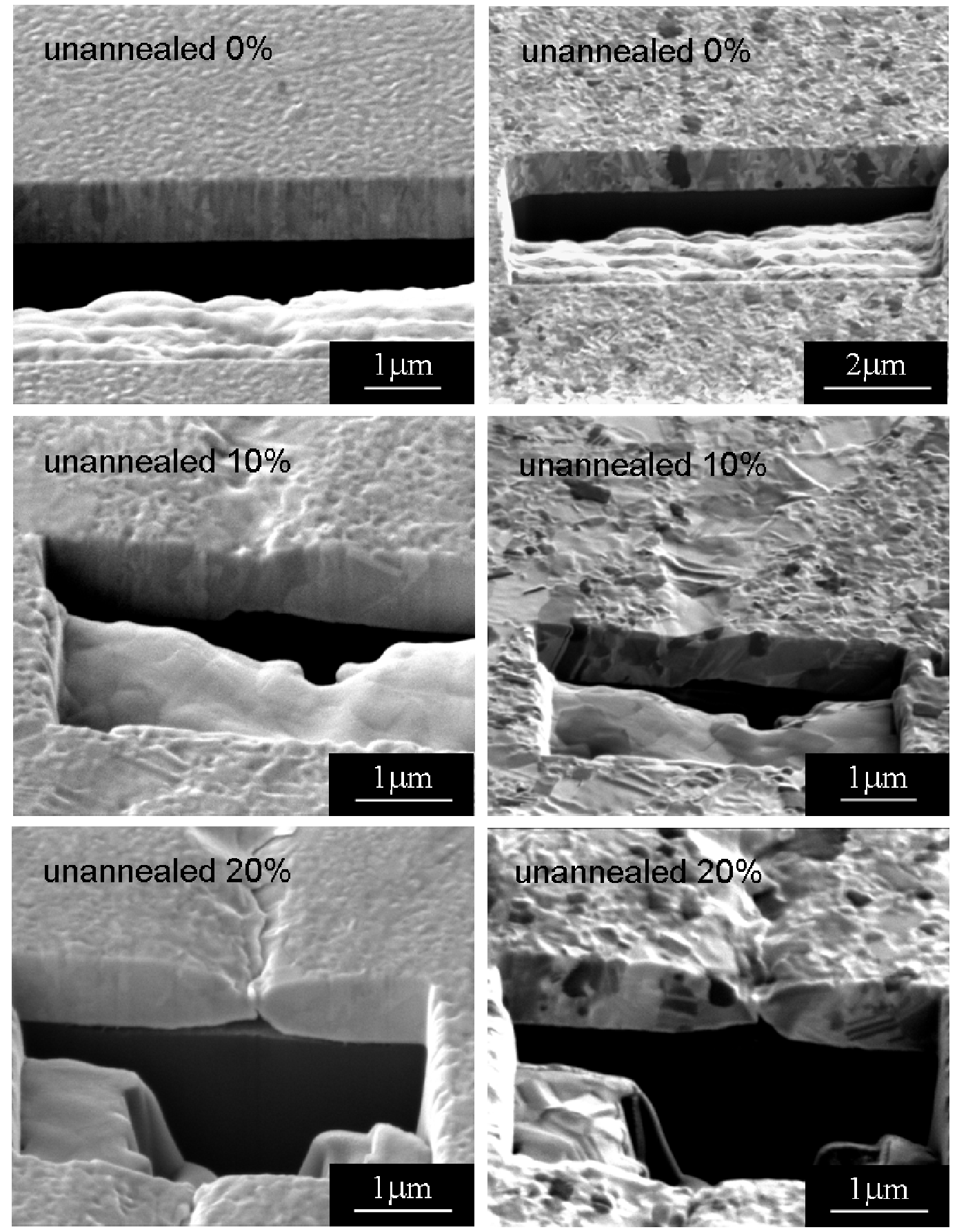

Figure 7. Cross sections created by using FIB. Images in the left column were taken by SEM, and images in the right column were taken by FIB.

(a) Undeformed film.

(b) Film pulled by

$10 \%$. (c) Film pulled by $20 \%$. We observe that strain localization is accompanied by interface debonding. 


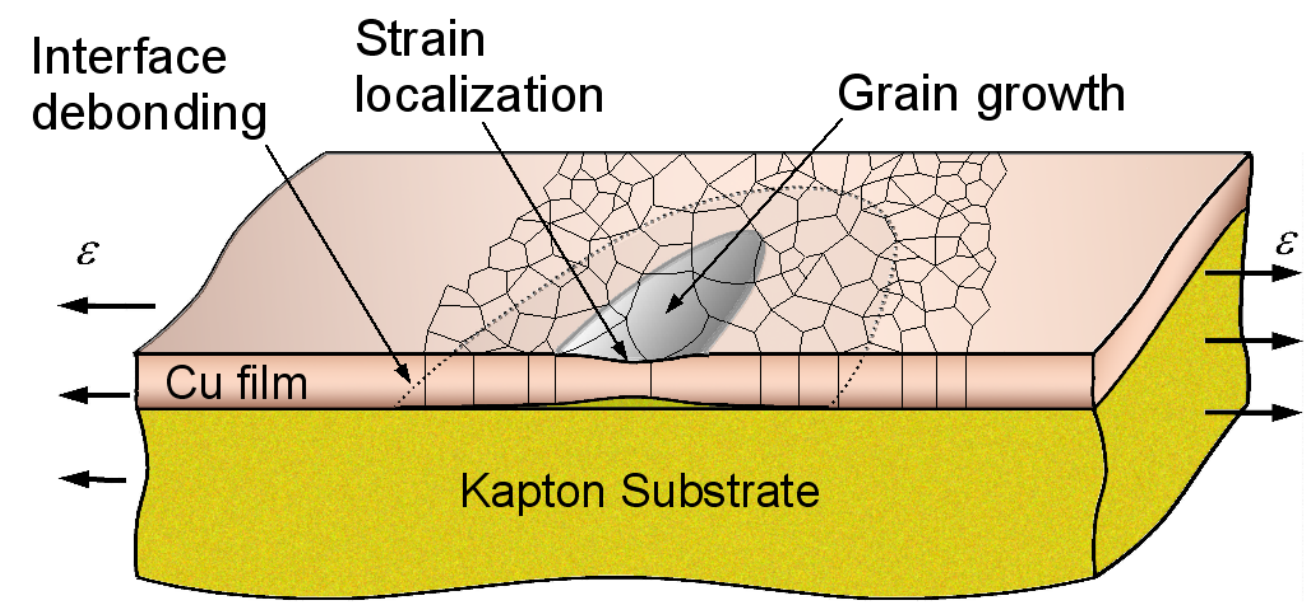

Figure 8. A schematic of concurrent processes: deformation-associated grain growth, strain localization promoted by large grains, and film/substrate interface debonding. The three processes co-evolve to form a neck. 